\title{
Outcome measures in mental health service research
}

\author{
HELLE CHARLOTTE KNUDSEN
}

Mental health service research is a relatively new area. It developed during the dawn of the deinstitutionalization era in the 1960s and has been rapidly expanding during the last decade. Outcome measures have been predominantly used to evaluate the effects of major changes in the health care system (Wing, 1972; Nielsen et al., 1981; Häfner et al., 1980; Tansella et al., 1991) and to compare the outcomes of different mental health care systems (Sytema, 1994; Sytema et al., 1989) and programs (Test $e$ t al., 1978). Unfortunately, the results of mental health service research have rarely made a major impact on the political and administrative level of planning and development of mental health services.

During the last few years the focus of utilization of outcome measures in mental health service research has changed dramatically. Limited financial resources for health care including mental health care and populations' growing needs and demands for care have changed the ideology of how to structure and organize health care systems in both Europe and USA; to day the health care systems operate more in accordance with market-based paradigms with purchasers and providers of care. In this arena, for purchasers of mental health care, evaluation of outcomes play an increasingly important role as indicators of the cost-effectiveness of services provided. At the same time all parties involved in mental health care show increasing concern for the quality of care provided. Politicians, administrators, purchasers, providers and consumers are employing the same outcome measures for mental health services utilized by researchers. There is an increasing recognition of a mutual interest to collaborate in defining the areas of outcome to be used in the assessments of

Indirizzo per la corrispondenza: Dr. H.C. Knudsen, Institute of Preventive Medicine, Copenhagen Health Services, Kommunehospitalet, DK-1399 Copenhagen K, (Denmark).

Fax + 45-33-324.240. services and in the developing of valid and reliable instruments.

At the latest American Psychiatric Association meeting: «Institute on Psychiatric Services» (formerly Institute of Community and Hospital Psychiatry), Boston October 6-10, 1995, managed care and outcome measures of mental health services were key issues. The American National Alliance for Mentally Ill (NAMI) presented a cooperative effort between purchasers (managed care executives), politicians (all stakeholders), providers of care (American Psychiatric Association), consumers of care and their close relatives (NAMI) and researchers to establish agreed «Principles of Consumer Outcomes Assessment» (National Alliance of Mental Health, 1995). The agreed principles, they state, «are meant to serve as guides when creating and implementing a system of clinical outcomes, or when evaluating an existing system»". They have agreed on 12 principles of outcomes assessment including important areas for mental health service outcome research. We wish to focus on two of these principles. Principle 2: «Outcome assessment tools and systems should always have demonstrated validity and reliability and must be sensitive to clinically important changes over time»; and Principle 11: «Outcomes assessments should use an appropriate scientific design and representative sample». These principles stress the need for researchers to develop a comprehensive set of valid and reliable outcome measures in mental health service research to comply with the agreed principles. This is one important step toward increasing interaction between researchers and other role players to make research results in outcomes of mental health service available for the planning and development of mental health care.

The first era of mental health service outcome research focused on the utilization at the system level of care; it focused on developing indicators of patients' utilization of services as in-, day and outpatients. Changes at the service level of care also aimed 
at improving mental health services to the general population by making mental health services more accessible, less stigmatizising and developing collaboration with other health and social services. Few research projects, however, have addressed outcomes of mental health status of the population, their needs for mental health service, or outcomes of other community services. (The other community services include social welfare offices, general practitioners, private practicing psychiatrists and volunteer organizations, etc.). Nor has research at the system level of care included mental health economic outcomes of services provided.

The deinstitutionalization process continued to develop during the 1970s and 1980s. It was intended that the provision of care should become community-based, comprehensive in approach and should target the persistent and severely mentally ill. Mental health service outcome research at the individual patient and program level emerged to help evaluate the extend to which these goals were attained. This included patient-related outcome measures such as 1) psychopathology and behavior, 2) general health status, including quality of life measures, sociability, patients' satisfaction with their general health status, 3) patients' satisfaction with services, and 4) their needs for care. During recent years the area of outcome measures at the program level has come to include evaluation of the burden to the family and the family's satisfaction with the services provided.

At the program level, research in mental health economic outcomes is now rapidly developing. The principles of cost-effectiveness, efficacy and efficiency of services are increasingly important for purchasers and providers of mental health care and are an important focus for research in assessing the impacts of different care programs.

Despite the increasingly critical importance of health economic considerations, this area has been neglected by researchers and consumer groups. For example, in their «Principles of Outcomes Assessment», NAMI does not mention economics.

At the program level of outcome, in a number of national settings, valid and reliable measures have been developed. But there still remains the task of evaluating these measures in other national settings.

There is good cross-national comparability of mental health care. This comparability has developed during the last two to three decades resulting in a number of treatment facilities which are highly internationally comparable. Almost all western mental health systems include emergency services, outpa- tient clinics, day-hospitals (partial hospitalization) rehabilitation services, group-home, staff supervised flats etc..

Despite this comparability, it is, never the less, important that when researchers compare services they take special care to provide standardized description of service and treatment modalities involved. An initiative to standardize characteristics of services has been taken by the World Health Organization, Regional Office for Europe in collaboration with the WHO Collaboration Center in Groningen, The Nederlands. They have developed a tool for classifying services providing mental health care (de Jong et al., 1991; de Jong, in press). These classifications includes the characteristics of curative care and rehabilitation. The instruments have been tested in several european countries and have proven to be valid and reliable in these settings. This standardization of definitions of mental health care modalities is an important step in enhancing comparability of outcome studies in the mental health field within and between countries.

While acknowledging the importance of the WHO initiative it is clear, that there are critical needs for internationally standardized, valid and reliable outcome measures in mental health service research. In 1992 a European network of researchers was established under the auspice of WHO, Regional Office for Europe - the European Network for Mental Health Service Evaluation (ENMESH). The aims of the network are to promote international collaboration on, developments and dissemination of study designs, research instruments, outcome indicators, relevant forms of statistical analyses and to be a clearing house for mental health service evaluation research in Europe. The network now includes more than 170 researchers from more than 20 European countries; important collaborative projects are developing.

Another important initiative in developing internationally standardized, valid and reliable outcome measures in mental health service research has recently been supported by an European Union Biomed 2 research grant supporting a concerted action project. This project's main aims are to complete these required tasks: 1) to develop and standardize measures and instruments in five defined areas of outcome in mental health services - need for care, family burden, satisfaction with services, mental health economics and service utilization; 2) to test these instruments for validity and reliability in an international setting; and 3 ) to conduct a com- 
parative study of outcome of services for persistent and severely mentally ill patients between the five participating countries.

It is increasingly clear to consumers, politicians and administrators that mental health service outcome research is an important tool in assessing and providing mental health care at the system and program level, and in the continuous process of assuring the quality of care. Mental health service research has come out of its isolated position as an interest for researchers only and has evolved into a discipline which can make important impact on the organization and development of mental health care systems and programs. Together with the recent initiatives to develop international research cooperation and international standardization of valid and reliable research instruments, mental health service outcome research has become a mature international research field with good possibilities for future international cooperative research.

\section{REFERENCES}

de Jong A. (in press). The WHO International Classification of Mental Health Care. A Tool for Classifying Services Providing Mental Health Care. WHO Collaborating Centre for Research and Training in Mental Health, University of Groningen and World Health Organization, Regional Office for Europe.

de Jong A., Giel R. \& ten Horn G.H.M.M. (1991). The WHO International Classification of Mental Health Care. A Tool for Classifying Services Providing Mental Health Care. Part 1. Curative Care. WHO Collaborating Centre for Research and Training in Mental Health, University of Groningen and World Health Organization, Regional Office for Europe.

Häfner H. \& Klug J. ( 1980). First evaluation of the Mannheim community mental health service. Acta Psychiatrica Scandinavica 62, Supplementum 285, 68-78.

National Alliance of Mental Health (1995). Principles of Consumers Outcomes Assessment Released. Dialogue on Outcomes on Mental and Addictive Disorders. Fall, 1-3.

Nielsen J., Nielsen J. A., Kastrup K. \& Strömgren E. (1981). The Samsø Project. A community psychiatric project in a geographically delimited population. Acta Jutlandica 55, Medicine Series 23.

Sytema S. (1994). Pattern of Mental Health Care; Methods and International Comparative Research. Drukkerij Van Denderen B.V.: Groningen.

Sytema S., Balestrieri M., Gavioli I., Giel R., ten Horn G. H. M. M., Micciolo R. \& Tansella M. (1989). Use of mental health services in South-Verona and Groningen. Acta Psychiatrica Scandinavica. 79, 153-162.

Tansella M., Balestrieri M. \& Micciolo R. (1991). Trends in the provision of psychiatric care 1979-1988. Psychological Medicine, Suppl. 19, :5-16.

Test M. A. \& Stein L. I. (1978). Community treatment of the chronic patient: research review. Schizophrenia Bulletin 4, 350-364.

Wing J. (1972). Evaluating a Community Psychiatric Service. The Camberwell Register 1964-1971. Oxford University Press: London. 